\title{
Key milestones during 40 years of behavioral medicine at the National Institutes of Health
}

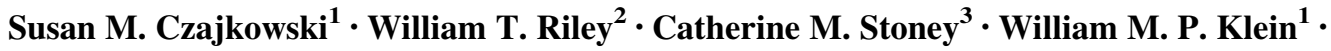 \\ Robert T. Croyle ${ }^{1}$
}

Received: August 25, 2018/Accepted: October 15, 2018/Published online: March 1, 2019

(C) This is a U.S. Government work and not under copyright protection in the US; foreign copyright protection may apply 2018

\begin{abstract}
The National Institutes of Health (NIH) has played a major role in promoting behavioral medicine research over the past 40 years through funding, review, and priority-setting activities and programs including scientific conferences, meetings, workgroups, intramural research, and training opportunities. In this review of $\mathrm{NIH}$ activities in support of behavioral medicine over the past four decades, we highlight key events, programs, projects, and milestones that demonstrate the many ways in which the NIH has supported behavioral and social sciences research and advanced the public health while contributing to the evolution of behavioral medicine as a scientific field.
\end{abstract}

Keywords National Institutes of Health · Funding and review of behavioral medicine research - Behavioral medicine infrastructures and programs at the NIH

Disclaimer The views expressed in this manuscript are those of the authors and do not necessarily represent the views of the National Institutes of Health or the U.S. Department of Health and Human Services.

Susan M. Czajkowski

Susan.Czajkowski@nih.gov

1 Division of Cancer Control and Population Sciences, National Cancer Institute, NIH, Bethesda, MD, USA

2 Office of Behavioral and Social Sciences Research, NIH, Bethesda, MD, USA

3 Division of Cardiovascular Sciences, National Heart, Lung, and Blood Institute, NIH, Bethesda, MD, USA

\section{Introduction}

Forty years ago, as Stephen Weiss, Gary Schwartz, Neal Miller, and other scientist-visionaries began developing the concepts and organizing a series of events that marked the beginning of the field of behavioral medicine, funding for research in this new area of science was in its infancy. Those seminal events-namely, the Yale Conference on Behavioral Medicine in 1977, the resulting definition of behavioral medicine (Schwartz \& Weiss, 1978a, 1978b) and the Institute of Medicine meeting that created the Academy of Behavioral Medicine Research in 1978 (ABMR Steering Committee Meeting, 1978)—brought influential figures in this nascent field together to develop the definitions, scope and vision for behavioral medicine as "the interdisciplinary field concerned with the development and integration of behavioral, psychosocial, and biomedical science knowledge and techniques relevant to the understanding of health and illness, and the application of this knowledge and these techniques to prevention, diagnosis, treatment and rehabilitation (Schwartz \& Weiss, 1978a, 1978b)."

Since that time, the National Institutes of Health (NIH) has played a major role in realizing this vision through the application of a wide array of funding mechanisms, development of behaviorally-oriented peer review groups, and initiation of priority-setting activities conducted via scientific conferences, meetings, workgroups, intramural research, and training opportunities. Although there have been and continue to be significant challenges and competing NIH priorities, the impact of NIH funding on behavioral medicine research is significant.

In advancing behavioral medicine research, the NIH has utilized both the broad-based funding of investigator-initiated health-related behavioral and social sciences 
research (BSSR) as well as targeted initiatives in specific areas of need and priority. Both the amount of funding and numbers of grants have increased over time, for a total of more than $\$ 4$ billion in funding for behavioral and social sciences research in FY2017. Using data available for extramural grants which dates back only to the mid-2000s and does not include contracts or other non-grant mechanisms, Fig. 1 shows the trend in amount of funding for BSSR grants over the past 10 years.

The growing presence and influence of behavioral medicine research at the NIH reflects a myriad of events, projects, and initiatives, some the result of years of careful planning, persistence and programmatic vision by NIH and extramural scientists (e.g., promoting research to improve weight loss strategies or to understand the health-related effects of physical activity), and others the result of unexpected events that thrust a particular disease or condition into the forefront of public health priorities (e.g., developing strategies for curbing HIV transmission). Describing the full history of the role and impact of NIH funding and policies on behavioral medicine over the past 40 years is not feasible in a single article. Rather than attempt a comprehensive history, we have chosen a more illustrative approach, highlighting key events, programs, projects, and milestones over the past four decades that demonstrate the many ways in which the NIH has supported behavioral and social sciences research and advanced public health while contributing to the evolution of behavioral medicine as a scientific field. We focus here on seminal events leading to initiatives or programs that have been highly influential in advancing public health as well as sustaining and expanding the role of behavioral medicine research at the NIH.

\section{The establishment and growth of behavioral medicine infrastructures at the NIH}

\section{Creation of BSSR funding and review programs}

The growth of behavioral medicine research as a field of study is tied to the creation and growth of individual BSSR-focused branches, programs and divisions within individual NIH Institutes in the 1970's and 1980's, the founding of the Behavioral Medicine Study Section in 1976, and the development and support for scientific organizations devoted to the advancement of behavioral medicine as a scientific field. Several early BSSR-focused additions to the NIH served to "prepared the soil" for the current set of NIH BSSR programs and activities. For example, the NICHD, which was established as an Institute in 1962, promoted a scientific vision that focused not only on the biomedical, but on the behavioral and social science aspects of human development. Indeed, the founding of

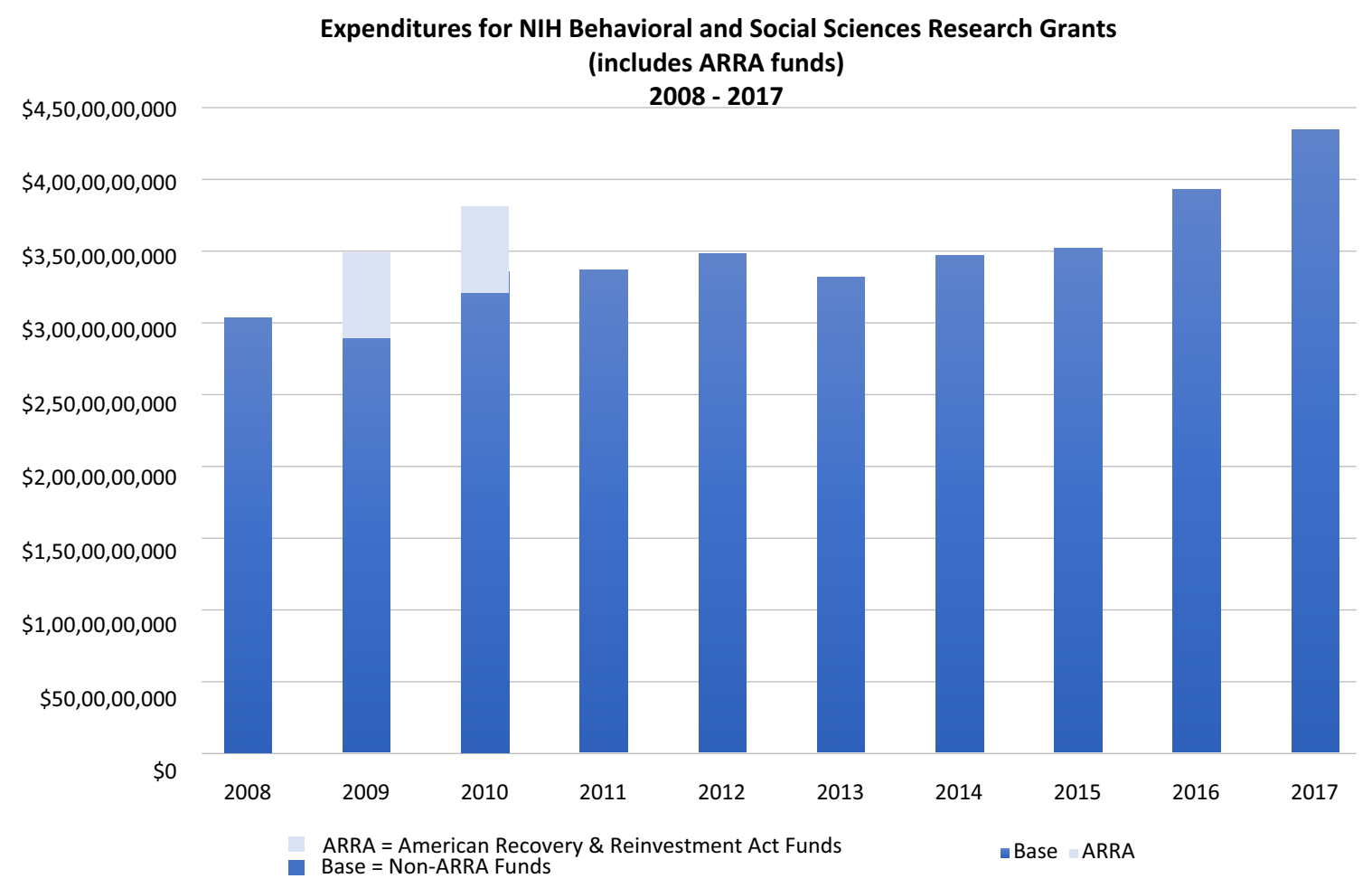

Fig. 1 Expenditures for NIH behavioral and social sciences research grants (includes ARRA funds) 2008-2017 
NICHD was a milestone in itself, as it represented the first time an NIH component viewed biobehavioral and social science research as integral to its mission (https://www. nichd.nih.gov/about/history). Similarly, the establishment of the NIA in 1974 represented an advance in behavioral medicine's representation in NIH, given its focus not only on the biological aspects of aging, but on the behavioral, neuropsychological, and social aspects as well.

In 1974, NHLBI took a step that led to transformative change in the promotion of behavioral medicine as a recognized field of study: Dr. Stephen Weiss became Chief of a branch at NHLBI that eventually became the Behavioral Medicine Branch. As Dr. Weiss recounts in a history of behavioral medicine at NHLBI, he was at the time essentially the only behavioral scientist at NHLBI, and the NHLBI portfolio contained only four regular research grants (R01s) focused on behavioral research (Weiss, 2013). At that time, behavioral grants at NIH were reviewed within existing study sections that often did not have the multidisciplinary expertise needed to address the wide range of behavioral topics being submitted. Dr. Weiss was instrumental in efforts to establish an NIH-wide Behavioral Medicine Study Section, which occurred in 1976 (Keefe, 2011) and enabled behavioral medicine research submitted to NIH to undergo peer review in a trans-NIH venue dedicated to BSSR. Dr. Weiss also played a critical role in the development of the 1977 Yale Conference on Behavioral Medicine, the 1978 meeting of the IOM hosted by David Hamburg, and the resulting formation of the Society of Behavioral Medicine (SBM) and Academy of Behavioral Medicine Research (ABMR), which resulted in increased recognition and credibility for this new scientific field. The SBM and ABMR have played major roles in nurturing the field, providing the opportunity for NIH scientists and NIH-funded investigators to share information about the latest findings and discuss trends and future needs in behavioral medicine research on an ongoing basis. It is notable that NIH scientists have played key roles in these organizations over the years, serving in leadership roles on their Executive Boards, Program Committees and Special Interest Groups.

Throughout the 1980's and 1990's, behavioral medicine research at the NIH flourished, with the creation or expansion of existing branches and programs of research and the establishment of several new Offices, Institutes, and Centers devoted to behaviorally-oriented research, such as the creation of the National Center for Nursing Research (NCNR) in 1985 (which became the National Institute on Nursing Research (NINR) in 1993), and the National Center for Complementary and Integrative Health, or NCCIH, first created in 1993 as the Office on Alternative Medicine in the NIH Office of the Director and converted to a Center in 1998 as the National Center for Complementary and Alternative Medicine (NCCAM).

The National Human Genome Research Institute (NHGRI) was developed in 1989 as the home of the Human Genome Project, and in 1990, established the Ethical, Legal and Social Implications (ELSI) Research Program as part of the Human Genome Project to "foster basic and applied research on the ethical, legal and social implications of genetic and genomic research for individuals, families and communities" (https://www.genome. gov/10001618/the-elsi-research-program/). The ELSI Research Program is an example of how a major NIH scientific area of interest-the Human Genome Projectspawned support for work on important social and psychological aspects of genetics and genomics; notably, its creation was made possible by a $3 \%$ percent ELSI set-aside from Congress. One of the distinctive aspects of the ELSI program, which was originally led Eric Juengst and then by Elisabeth Thomson, is that it was explicitly multidisciplinary and completely open to all research methods, including archival, qualitative, survey and experimental methods (Meslin et al., 1997). The program has supported multiple meetings and other events and used a wide variety of mechanisms (e.g., Centers of Excellence, standard research grants, postdoctoral fellowships) to build needed capacity in this area.

The ELSI program represents a milestone in NIH's history as a prerequisite for the later creation of the Social and Behavioral Research Branch, an intramural branch at NHGRI launched in 2003 to focus on social and behavioral processes related to genetics and genomics. The inaugural leader of the branch was Dr. Colleen McBride, who quickly developed a seminal project examining how people respond to a variety of types of genetic feedback (e.g., Kaphingst et al., 2012). The branch has been instrumental in the integration of behavioral medicine into genomic research, and stands as one of the few intramural branches at NIH devoted exclusively to behavioral and social sciences research.

At the National Cancer Institute (NCI), the Division of Cancer Control and Population Sciences was created in 1997 under the leadership of Dr. Barbara Rimer, Dr. Robert Hiatt, and (later) Dr. Robert Croyle (who joined NCI in 1998), to "enhance NCI's ability to alleviate the burden of cancer through research in epidemiology, behavioral sciences, health services, surveillance, and cancer survivorship." The Division has since evolved into a model for supporting research on cancer-related psychological and behavioral processes, health behaviors (including tobacco use), communication strategies, healthcare processes and outcomes of care, and translation of knowledge about cancer treatment and survivorship into practice and com- 
munity settings (https://cancercontrol.cancer.gov/od/ history.html).

Although visionary leadership was needed to initiate and develop this behavioral medicine research presence throughout the NIH, much of the lasting, sustainable progress in establishing behavioral and social sciences research as an important area within the NIH is attributable to the numerous BSSR scientists, analysts, and other staff members hired into many of the Institutes, Centers and Offices at NIH over the past 40 years. These individuals have been instrumental in the growth and nurturing of behavioral medicine at the $\mathrm{NIH}$, as they brought (and continue to bring) their behavioral medicine research expertise, training, dedication and vision to bear on implementing the early vision of the field's leaders at the NIH.

\section{The creation of OBSSR}

A milestone in recognition of the importance of behavioral and social factors in health and illness was achieved in 1995 with the creation of NIH Office of Behavioral and Social Sciences Research (OBSSR) within the Office of the NIH Director.

OBSSR was enacted by Congress in 1993 to identify projects of behavioral and social sciences research that should be conducted or supported by the national research institutes and develop such projects in cooperation with such institutes, and to coordinate research conducted or supported by the agencies of the National Institutes of Health (42 USC, 283c, 1994). The creation of the OBSSR was the result of many efforts in the years preceding its enactment (Kaplan et al., 2017). The annual NIH OBSSR Distinguished Lecturer Award is named in honor of Matilda White Riley who was an early coordinator of and spokesperson for the behavioral and social sciences across the NIH (Mechanic, 2018). Soon after joining NIH, she cochaired the NIH Steering Committee for the Institute of Medicine's "Health and Behavior: Frontiers of Research in the Biobehavioral Sciences" (National Research Council, 1982). This influential report provided the basis for the eventual creation of the NIH OBSSR by highlighting the shift in burden of disease from acute to chronic conditions, the substantial role of behavior in contributing to these conditions, the application of scientific methods to gain a better understanding of human behavior, and the inadequate funding for biobehavioral research (Table 1).

Soon after the office was formed in 1995, OBSSR released its first strategic plan focused on three priorities: (1) Enhance Behavioral and Social Sciences Research and Training; (2) Integrate Biobehavioral Perspectives; and (3) Improve Communications Among Behavioral and Social Science Researchers and the Public. One key principle in the early development of the OBSSR is that "although discoveries in the behavioral and social sciences are as critical for health as those from the biomedical sciences, knowledge from both areas must ultimately be integrated" (Anderson, 1997). This integration of behavioral and social sciences within the broader biomedical research enterprise continues to be guiding philosophy of the office. Among the accomplishments in the decade that followed was the establishment of the Behavior Change Consortium (BCC; Solomon and Kington, 2002), a trans-NIH effort among 17 Institutes and Offices of the NIH to address disease prevention strategies related to tobacco use, excessive alcohol use, unhealthy diet, and inactivity. Communicating the important role of social and behavioral influences on health and the value of BSSR to addressing these influences was critical to changing the perspectives of those in leadership at the NIH during that time.

The second strategic plan, released in 2007, extended the previous priorities and focused on four priorities: nextgeneration basic science, interdisciplinary research, systems science, and problem-based focus for population impact (Mabry et al., 2008). Among the accomplishments in the decade that followed this plan was the promotion of transdisciplinary research in areas such as health disparities (Abrams, 2006), the advancement of systems science approaches in the social and behavioral sciences (Mabry \& Kaplan, 2013), the development of a dissemination and implementation research and training effort (Meissner et al., 2013), and the support of the emerging area of mHealth (Nilsen et al., 2013).

The current strategic plan, 2017-2021 (OBSSR Strategic Plan, 2017), focuses on three scientific priorities that have been further elaborated in a series of commentaries:

- Improve the Synergy of Basic and Applied Behavioral and Social Sciences Research (Riley, 2017a).

- Enhance and Promote the Research Infrastructure, Methods, and Measures Needed to Support a More Cumulative and Integrated Approach to Behavioral and Social Sciences Research (Riley, 2017b).

- Facilitate the Adoption of Behavioral and Social Sciences Research Findings in Health Research and in Practice (Riley, 2017c).

Integration of behavioral and social sciences with the larger biomedical research enterprise continues to be a key aspect of OBSSR efforts, particularly for large transdisciplinary projects like the Environmental Influences of Child Health Outcomes (ECHO; Gillman \& Blaisdell, 2018), Adolescent Brain and Cognitive Development (ABCD; Volkow et al., 2018) and All of Us (Riley et al., 2015).

Over the 23 years of its existence, OBSSR has served as a conduit, and sometimes as a lightning rod, for addressing the various challenges of behavioral and social sciences 
Table 1 OBSSR Directors 1995-present

\begin{tabular}{ll}
\hline OBSSR directors & Term of service \\
\hline Norman Anderson, Ph.D. & $1995-2000$ \\
Peter Kaufmann, Ph.D. (Acting) & 2000 \\
Raynard Kington, M.D., Ph.D. & $2000-2003$ \\
Virginia Cain, Ph.D. (Acting) & $2003-2005$ \\
David Abrams, Ph.D. & $2005-2008$ \\
Christine Bachrach, Ph.D. (Acting) & $2008-2010$ \\
Deborah Olster, Ph.D. (Acting) & $2010-2012$ \\
Robert M. Kaplan, Ph.D. & $2012-2014$ \\
William T. Riley, Ph.D. & $2014-$ present \\
\hline
\end{tabular}

research at the NIH. The office fields queries from Congress, other federal agencies, NIH leadership, and various professional organizations regarding the role of BSSR at the NIH and the science policies that affect this research. It serves as a clearinghouse for information about the opportunities and challenges of BSSR across the NIH. Via its coordination functions, it brings together behavioral and social science staff from among the NIH institutes and centers to develop trans-NIH initiatives, identify BSSR gaps not addressed by the individual institutes and centers, and advocate for support of rigorous and impactful behavioral and social sciences research at the NIH.

\section{The value of behavioral medicine at the NIH: responding to public health challenges}

Behavioral medicine research has played a key role in NIH's response to major public health challenges over the past 40 years. In this section, we highlight two such challenges-the HIV/AIDS crisis and tobacco prevention and control efforts-to illustrate how behavioral research advances were critically important elements in the NIH's portfolio of research addressing these public health challenges and thus demonstrate the importance of behavioral and social science research in advancing the public health, while also stimulating advances in behavioral science research related to health.

\section{The HIV/AIDs crisis}

In June of 1981, the Centers for Disease Control and Prevention (CDC) published a report documenting the first five cases of AIDS in the United States (U.S. Centers for Disease Control and Prevention, 2001). Since that time, HIV/AIDS has become a worldwide epidemic, taking the lives of 30 million people with 33.3 million more currently living with the disease (Faster Cures, 2011). Recognition of
HIV/AIDS as a global crisis and the subsequent development of life-saving and life-extending treatments for patients, as well as the design of effective preventive measures, is a major success story for the biomedical and behavioral science enterprise. The HIV/AIDS crisis, and the response by NIH and other federal agencies, has also had an enormous impact on behavioral medicine by stimulating increased NIH support for research on prevention of both communicable and non-communicable diseases and strategies to improve adherence to complex treatment regimens such as antiretroviral therapies, while highlighting the importance of stakeholder engagement and the patient's voice in the design, testing and implementation of preventive and treatment regimens.

In 1983, Congress established the NIMH AIDS research program, which focused on behavioral science and HIV prevention and was followed by the creation of the NIH Office of AIDS Research (OAR), which was charged in 1988 with coordinating HIV research across the NIH. Establishment of these entities at the NIH has been pivotal in the development of knowledge critical to understanding, treating and preventing the spread of HIV.

Behavioral medicine efforts to address the HIV/AIDS crisis increased rapidly, especially at the NIMH, between 1983 and 1995 (Stover \& Pequegnat, 2013), and included a number of initiatives focused on reducing HIV risk through use of condoms and developing interventions to improve adherence to the complex retroviral treatments needed to manage HIV/AIDS as a chronic disease. NIMH's Office of AIDS Research was also at the forefront in its focus on vulnerable groups and those with multiple morbidities-for example, minority and disadvantaged populations, homeless individuals, sexual minorities, and those with co-occurring substance use disorders and mental illnessleading to the development of preventive interventions for those most affected by the disease and least likely to be reached with conventional approaches (Mental Health Matters, 2009). The success of HIV/AIDS preventive interventions is reflected in a review by Stall et al. (1988) that documented the rapid adoption of condom use among gay men in the early days of the AIDS crisis and concluded that "AIDS education and prevention campaigns have resulted in the most profound modifications of personal health-related behaviors ever recorded (Stall et al., 1988)." Given the stigmatization and highly politicized nature of the disease, its spread predominately via sexual activities, and the vulnerable groups most affected by the disease, it took considerable determination and persistence at the time on the part of both the NIH staff and the extramural researcher community to advance this research agenda.

With the advent of effective combination therapy for HIV/AIDS in the late 1990s, the focus shifted to the development and testing of interventions to improve 
adherence to these treatments, a critical issue given that high levels of adherence were needed to prevent the development of more resistant strains of HIV. NIMH developed the first HIV adherence research Funding Opportunity Announcement (FOA) in 2001 (https://grants. nih.gov/grants/guide/pa-files/PA-01-073.html) and has been a leader in stimulating research to design and test more effective adherence strategies for HIV/AIDS treatments since that time. Indeed, our understanding of how best to intervene to improve adherence to complex treatment regimens has been greatly influenced by the work on adherence in HIV/AIDS.

\section{Tobacco control research}

Together with many other stakeholders at the federal and state level, NIH has contributed to one of the most important public health success stories of the past 40 years: the recognition of tobacco use as an important cause of disease, including cancer, cardiovascular and pulmonary diseases, and the subsequent design, testing and implementation of successful efforts to reduce smoking rates and thus the incidence and mortality from smoking-related diseases. From 1965 to 2014, the prevalence of cigarette smoking among US adults decreased from 42.4 to $16.8 \%$ (Ginexi \& Vollinger, 2016; Office on Smoking and Health, 1965-2014), resulting in the prevention of an estimated 8 million US deaths and the addition of nearly 2 decades of life to the beneficiaries (Holford et al., 2014).

Much remains to be done, including work to reduce disparities in tobacco use and tobacco-related disease among some populations, such as lower SES individuals, individuals with mental health conditions, LGBT populations, and veterans and members of the military (https://cancercontrol. cancer.gov/brp/tcrb/monographs/22/index.html). In addition, the advent and increasing use of e-cigarettes pose additional questions regarding the health impact, use behaviors, and addiction potential of these and other nicotine delivery devices, which are actively being addressed by NCI, NIDA, NHLBI and other NIH institutes. Nevertheless, the reduction in smoking and consequent reduction in tobacco-related disease and death is testament to the progress that can be achieved when behavioral research is part of a coordinated, focused, and multilevel set of efforts aimed at changing policies, social norms, and the behaviors of individuals.

In the early years, when the effects of tobacco use on health were the subject of heated public and scientific debate, the NIH conducted and supported important epidemiologic and basic biological and mechanistic studies demonstrating the causal relationship between smoking and disease (Parascandola, 2001). Additionally, as part of the early work on tobacco, NIH epidemiologists and biostatisticians developed novel methods for analyzing and evaluating data from epidemiologic studies of cancer risk factors. This research was critical to the highly influential 1964 Surgeon General's Report which concluded, among other things, that cigarette smoking is a cause of lung cancer in men and a probable cause of lung cancer in women, and that the magnitude of the effect of cigarette smoking far outweighs all other factors. The report's scientific conclusions, and its delineation of the many areas in which the science remained unclear at the time, helped usher in succeeding decades of research, advocacy, and eventually, the implementation of programmatic and policy interventions that have been instrumental in reducing smoking and improving the public health.

Research funded by the newly created National Institute on Drug Abuse (NIDA) in the late 1970's and early 1980's was critical in demonstrating that tobacco use was not simply a "habit" or a "personal choice;" rather, tobacco dependence was shown to involve a complex array of social, psychological, behavioral and biological mechanisms - namely physiological addiction to nicotine (Parascondola, 2011; Office on Smoking and Health, Office of the Surgeon General, 1988). This paved the way for decades of research investigating tobacco as a physically addictive substance, which in turn led to the development, testing and implementation of interventions that targeted multiple levels of influence-from biological (pharmacotherapy), behavioral (smoking cessation programs) and environmental (policy) interventions. In addition, findings from NIH-funded research on the causal relationship between exposure to secondhand smoke and disease helped lead to important environmental and policy changes aimed at eliminating tobacco smoking in indoor (and, more recently, some outdoor) environments. The resulting "smoke-free" policies and laws protect nonsmokers from exposure to secondhand smoke, reduce smoking prevalence among smokers, change social norms about smoking, and helped bring about a marked decline in the social acceptability of smoking (https://cancercontrol.cancer.gov/ brp/tcrb/monographs/21/index.html).

In the early 2000s, NCI led efforts that funded the study and analysis of formerly secret tobacco industry documents made available to the public through litigation and other means. The resulting studies transformed public understanding of the role of the tobacco industry and its allies in promoting tobacco use in the U.S. and abroad and contributed to, among other things, greater understanding of the influence of tobacco product design and marketing on smoking behavior. In addition, the NCI tobacco control monograph series has contributed important new findings to the field. For example, Volume 19, "The Role of the Media in Promoting and Reducing Tobacco Use," (2008) found that the weight of the evidence demonstrates a causal relationship between tobacco advertising and promotion 
and increased tobacco use. The 2000's also saw the first large-scale investment by the NIH in global tobacco control research, led by the Fogarty International Center (FIC) and contributing to research capacity for tobacco control in many low- and middle-income countries (Berg et al., 2018).

The NIH, and in particular the Institutes most involved in funding tobacco research (NCI, NIDA and NHLBI), were also key players in the development of evidencebased interventions ranging from individual-level smoking cessation interventions delivered by clinicians (NCI Smoking and Tobacco Control Monograph 5), to developing implementation strategies for delivery of evidencebased cessation strategies to vulnerable populations (Riley et al., 2012; Rigotti \& Stoney, 2016), through environmental changes and policies that have been shown to significantly prevent smoking and tobacco use (Ginexi \& Vollinger, 2016). Major initiatives such as the Community Intervention Trial for Smoking Cessation (COMMIT), begun in 1988 (National Cancer Institute, 1995), and the American Stop Smoking Intervention Study (ASSIST) begun in 1991 (National Cancer Institute, 2005, 2006), were especially important in demonstrating the effectiveness of large-scale smoking cessation and prevention programs and policies (National Cancer Institute, 2012). The NCI's State and Community Tobacco Control Research Initiative, begun in 2011, focused on policies related to secondhand smoke, tax and pricing, and media and marketing strategies through both large-scale research projects and time-sensitive pilot studies based on input from state and community partners and the CDC (Schmitt et al., 2014). Today, NCI's Smokefree.gov initiative, now in its 15 th year, provides free, evidence-based quit assistance to millions of visitors each year through a variety of web and mobile platforms (https://smokefree.gov).

The passage of the Family Smoking Prevention and Tobacco Control Act in 2009 granted FDA authority to regulate the manufacture, marketing, and distribution of tobacco products to protect public health. As result, the NIH and FDA formed the Tobacco Regulatory Science Program (TRSP), overseen by the NIH Office of Disease Prevention, to establish a comprehensive research agenda in tobacco regulatory science and to foster tobacco regulatory research. Since its inception, the TRSP has implemented the trans-HHS collaborative between the Institutes and Centers of the National Institutes of Health (NIH) and the Food and Drug Administration's (FDA) Center for Tobacco Products (CTP) and provided support to numerous investigators to conduct tobacco regulatory research.

Ultimately, NIH's tobacco control research activities can be viewed as one of the major behavioral and public health success stories, highlighting the importance of intervening at multiple levels from individual-level smok- ing prevention and cessation programs through policy and environmental efforts, as well as the benefits of creating and sustaining partnerships with other key federal stakeholders such as the FDA and the CDC.

\section{The advance of randomized behavioral clinical trials: improving our science to improve the public health}

The randomized controlled trial (RCT) has historically been the "gold standard" by which biomedical treatments are determined to be safe and efficacious in preventing and treating a range of diseases, from cardiovascular diseases to diabetes and cancer, among many others. The application of this methodology to behavioral interventions resulted in identification of effective behavioral approaches to modify risk factors and improve disease outcomes that were persuasive to the biomedical research establishment. The 1990's saw initiation and completion of two major multi-site behavioral clinical trials that are highlighted here due to their high visibility, the role they played in moving the science forward in their respective fields, and the lessons they can convey about the value and challenges associated with designing and conducting rigorous NIH-funded randomized behavioral clinical trials.

\section{The Diabetes Prevention Program (DPP)}

The Diabetes Prevention Program (DPP) was a randomized, multi-center clinical trial initiated by the National Institute on Diabetes and Digestive and Kidney Diseases (NIDDK) in 1995 that compared the ability of an intensive behavioral intervention emphasizing healthy dietary patterns and physical activity, versus a drug, metformin, versus a usual care control group, to delay or prevent the onset of type 2 diabetes in adults with impaired fasting glucose or prediabetes. Results of prior research showed not only that individuals with prediabetes face a high risk of developing diabetes, but that substantial and significant changes in diet and physical activity behaviors were possible with intensive lifestyle intervention. The DPP was thus based on over 30 years of prior behavioral and biomedical research, from observational to experimental studies, that translated basic behavioral concepts and findings-for example, from classical conditioning and social learning theory-to produce incremental changes in the ability to produce weight loss through diet and physical activity.

The DPP was begun in 1996, and enrolled 3234 adults with impaired glucose tolerance, randomizing them to receive either intensive lifestyle intervention, metformin, 
or usual care, and following them for incidence of diabetes. In July of 2001, the Data Safety and Monitoring Board (DSMB) recommended early termination of the trial. While both the lifestyle intervention and metformin were found to be superior to usual care in preventing Type 2 diabetes (Diabetes Prevention Program Research Group, 2002), participants who lost weight through dietary changes and increased physical activity significantly reduced their chances of developing diabetes relative to taking metformin and to usual care. The results showed that a $7 \%$ weight reduction and $2.5 \mathrm{~h}$ per week activity increase led to a $58 \%$ reduction in the cumulative incidence of Type 2 diabetes in older insulin-resistant individuals, thus illustrating the potential of behavioral interventions to affect clinically important outcomes of importance to the "endusers" of medicine.

The success of the DPP illustrates the importance of a long-term progressive approach to developing robust and efficacious behavioral interventions for disease risk factors, and the value of testing these approaches in large-scale, randomized behavioral clinical trials in order to maximize the impact of the findings and their ability to influence clinicians in practice settings. Current research is focusing on developing the best methods for translating these findings to clinical care and community settings, and recently the Centers for Medicare and Medicaid Services (CMS) has agreed to reimburse providers for administering the DPP intervention following a successful demonstration project (Centers for Medicare and Medicaid Services, 2017).

\section{The Enhancing Recovery in Coronary Heart Disease (ENRICHD) Patients Study}

In the early 1990's, evidence had accumulated implicating two psychosocial factors as increasing the risk of death and adverse outcomes in patients with myocardial infarction (MI). Social isolation and low levels of social support were found in several studies to confer risk of MI recurrence in MI and CHD patients (Berkman et al., 1992; Williams et al., 1992) and similarly, depression in MI and CHD patients was associated with risk of death and recurrent MI (Frasure-Smith et al., 1993). Furthermore, these associations demonstrated a dose-response relationship (Lespérance et al., 2002) and plausible biological mechanisms existed to account for them (Bradley \& Rumsfeld, 2015). Based on this evidence, in June 1992 an NHLBI Working Group convened to assess the evidence and recommend next steps, eventually recommending that NHLBI conduct a clinical trial in cardiac patients to test the effect of treating depression and perceived lack of social support on clinical cardiac endpoints.

The Enhancing Recovery in Coronary Heart Disease (ENRICHD) Patients Study began recruitment in 1996, and eventually enrolled 2481 patients with low social support or depression, recruited within 28 days after a myocardial infarction. The psychosocial intervention consisted of cognitive behavioral therapy (CBT) adapted for MI patients, or a social support intervention that focused on addressing perceived low social support and enhancing network support, or both (The ENRICHD Investigators, 2000). The primary endpoint was a composite of all-cause mortality and non-fatal myocardial infarction; several secondary endpoints were also assessed. Patients were followed for an average of 29 months.

Results showed that the depression and social support intervention produced statistically significant but only modest improvements in depression and social isolation and did not affect the primary endpoints of death or recurrent MI (Berkman et al., 2003). These findings, while disappointing, may reflect the smaller than expected depression and social support differential between treatment and usual care as well as lack of an optimized treatment for low social support. Subsequent trials of depression treatment have demonstrated stronger effects with more robust, collaborative depression treatment approaches (Davidson et al., 2013). The ENRICHD trial results point to the importance of developing and optimizing psychosocial and behavioral interventions to ensure they are maximally intensive, robust, and can produce clinically meaningful, not just statistically significant, changes in psychosocial risk factors of interest, especially when trial outcomes involve clinical endpoints.

\section{Increasing rigor in behavioral trials research}

Conducting clinical trials of behavioral interventions requires deep knowledge of standard clinical trial principles of randomization, control groups, sources of bias, masking, equipoise, analytic strategies appropriate for the design proposed, power estimates, and design strategies. In addition, several unique complexities in behavioral clinical trials that do not arise in trials of pharmacologic agents (e.g., lack of ability to double-blind; selection of an appropriate control or comparator group given there is no "behavioral placebo") must be addressed thoughtfully and carefully.

In 2001, with support from the Office of Behavioral and Social Science Research (OBSSR), the first Summer Institute on Conducting Randomized Behavioral Clinical Trials was established. A 2-week residential program ensured dedicated time for learning and consultation with a range of world experts in clinical trial design, conduct, and analysis. Since its inception, the Institute has supplemented the types of research methods courses typically provided during graduate and post-graduate training. Although graduate school programs typically include training in 
experimental as well as quasi-experimental methods, training opportunities in the design and conduct of traditional RCTs-which are complex forms of field experiments-are generally not widely available to graduate students in the behavioral sciences. The Institute was designed to include specialized training in the unique complexities that characterize behavioral trials to ensure these trials are conducted as rigorously as possible.

Today, the Summer Institute continues to train promising young investigators who are developing, designing, and conducting behavioral RCTs (https://obssr.od.nih. gov/training/training-supported-by-the-obssr/institute-onrandomized-behavioral-clinical-trials/). Fields represented by the approximately 700 Fellows who have successfully completed the training institute over the last 18 years include $\mathrm{PhDs}$ and MDs conducting behavioral research in clinical, developmental, quantitative, and experimental psychology; sociology; rehabilitation science; nursing; oncology; cardiology; emergency medicine; public health; and many others. More recently, the Summer Institute has expanded its methodological focus to include newer trial designs, such as the Multiphase Optimization Strategy (MOST) and the Sequential Multiple Assignment Randomized Trial (SMART) design (Collins et al., 2007). The Summer Institute has also become a model for other training efforts, with OBSSR and individual Institutes expanding the topics of Summer Institute programs to include optimization designs, community-based participatory research, mixed method designs, mHealth research, and the use of health behavior theories in the design of behavioral interventions (see https://obssr.od.nih.gov/training/training-supported-by-theobssr/ for a list of current OBSSR-supported training programs).

\section{Beyond the randomized clinical trial: promoting behavioral medicine research across the translational spectrum}

\section{Basic behavioral and social science research (bBSSR)}

The NIH has a long history of investment in basic or foundational research (Collins et al., 2016), but the investment of basic behavioral and social science research (bBSSR) has been a long-standing concern of the research community. In 2004, the NIH established a Working Group of the Advisory Committee to the Director (WG-ACD; $\mathrm{NIH}, 2004)$ to examine basic behavioral and social research across the NIH. Two issues led to the establishment of this working group and its subsequent report. First, NIMH reorganized and shifted priorities to research more closely aligned with its vision to prevent and cure mental illness, which resulted in the elimination of support for basic behavioral and social sciences research that could not make a strong translational argument for its relevance to mental illness or was not closely tied to basic brain science (Holden, 2004). Second, NIGMS, as the primarily basic science institute of the NIH, was viewed by the research community as an appropriate home for basic BSSR and was encouraged by Congress to do so (Kraut, 2004).

The report highlighted a number of basic BSSR findings that have shaped our understanding of health and illness as well as emerging opportunities in basic BSSR with a plausible pathway to being translated to improve health. The WG-ACD recommended that NIH establish a secure and stable home for basic BSSR to foster this research when it is not closely aligned with the disease-focused or categorical institutes and centers. It also recommended that basic BSSR potentially applicable to specific diseases, conditions, or developmental periods, and currently supported by the categorical institutes and centers, should continue. The report indicated that OBSSR could play a greater role in developing basic BSSR priorities, initiatives and funding via increased planning and budgetary authority.

NIGMS did not expand funding for basic BSSR or become the secure and stable home for this science as the WG-ACD envisioned, nor did the OBSSR receive increased planning and budgetary authority to support basic BSSR. Under continuing encouragement from the research community and from Congress to address this issue, in 2009, the NIH initiated the Basic Behavioral and Social Science Opportunity Network, or OppNet (https:// oppnet.nih.gov/). Supported initially by funds from the American Recovery and Reinvestment Act (ARRA) and a tap (or tax) on the NIH ICs, OppNet sought to advance basic behavioral and social science research on the nature of behavior and social systems, and to expand the bBSSR portfolio by opening opportunities to investigators not previously supported by the NIH. Over a five-year period with a budget of approximately $\$ 85$ million, OppNet released 23 Funding Opportunity Announcements resulting in 151 grant awards studying a range of basic processes and mechanisms in areas such as self-regulation, sleep, stress, behavioral maintenance, decision making, multisensory processing, epigenetics, social environment effects on health, and culture on health. OppNet also funded a variety of training opportunities, particularly for expanding the basic science skills of mid- and senior-level career researchers. An evaluation of the OppNet program concluded that the OppNet researchers were productive, both in publications and in citations from their publications, and that approximately $30 \%$ of grantees were first time $\mathrm{NIH}$ grantees who conducted research in areas of bBSSR unique 
to NIH (https://oppnet.nih.gov/wp-content/uploads/2017/ 11/OppNet-evaluation-executive-summary.pdf).

Following this five-year funding period, OppNet continues as a voluntary funding effort with OBSSR matching the funding of the ICs to support basic BSSR that is trans$\mathrm{NIH}$ in nature, focused on seeding new or emerging domains of basic BSSR and developing new basic BSSR investigators. While OppNet continues to support basic BSSR via this voluntary model, greater support for trans-IC basic BSSR that has a plausible translational pathway to health is clearly needed.

Fortunately, basic BSSR funded by the ICs has increased over the past few years, from $\$ 1.23$ billion in FY14 to \$1.99 billion in 2017 (RCDC; https://report.nih. gov/categorical_spending.aspx). Some of this increase has been the result of a number of brain research initiatives including the BRAIN Initiative and Alzheimer's research. The first 5 years of the BRAIN initiative have focused on neurotechnologies, but the second phase, beginning in 2021, will shift focus to integrating these neurotechnologies to make new discoveries about the brain and behavior, consistent with its overarching vision to combine "these approaches into a single, integrated science of cells, circuits, brain, and behavior." (NIH, 2014). This second phase of BRAIN should advance basic BSSR in the cognitive and behavioral neurosciences. The twenty-first century Cures Act provided increased funding not only for the Brain Initiative but also for Alzheimer's Research, and these increased sources of funding should improve support for basic BSSR, particularly in the brain, behavior, and cognitive sciences (Riley \& Blizinsky, 2017).

\section{Early-phase behavioral translation research}

NIH's mission of “Turning Discovery into Health" reflects its emphasis on translational research, often defined as "the process of applying ideas, insights, and discoveries generated through basic scientific inquiry to the treatment and prevention of human disease" (Editorial, 2004). Early on, translational research was categorized as consisting of two stages: T1 research, or "the translation of basic science discoveries into clinical studies," and T2 research, or the translation "of clinical studies into medical practice and health decision-making in systems of care" (Sung et al., 2003). More recently, additional categories of the translational spectrum have been defined (e.g., Khoury et al., 2007; Fishbein et al., 2016) and there have been attempts to achieve consensus among researchers regarding number and definition of translational stages (Fort et al., 2017).

While early-phase translational research (i.e., T1 research) is usually defined within the context of biomedical rather than behavioral and social sciences research, T1 behavioral research, or the translation of basic behavioral and social science discoveries into health-promoting interventions, is an essential step in the development of new, more effective behavioral strategies to encourage behaviors shown to reduce disease and disability, such as smoking cessation, physical activity, healthy diets, and adherence to life-saving medical regimens and treatments. Since the 1980's, the NIH has been at the forefront of development and application of strategies for improving the translation of basic behavioral science discoveries into practical strategies to improve health as reflected in a variety of funding initiatives, workshops and conferences. While one could argue that behavioral interventions have always been designed based on behavioral theories and labbased findings, recognition of T1 or early-phase behavioral translation research as an area of science in its own right and deserving of support from targeted funding opportunities is a relatively recent phenomenon, occurring largely within the past 40 years (Czajkowski et al., 2016).

$\mathrm{NIH}$ Institutes such as NIMH and NIDA were early leaders in promoting recognition of and funding for earlyphase translational behavioral research. In 2000, the NIMH's Advisory Council released a report on "Translating behavioral science into action" (DHHS, 2000) which outlined challenges to the integration of basic and clinical scientists in mental health research, including different funding sources for basic versus clinical scientists (e.g., NSF vs. NIH funding); institutional policies and structures, e.g., housing of basic and clinical scientists in different locations, cost-sharing of indirect costs (working across departments often entails giving up indirect costs); and cultural issues, including the "siloing" of academic programming and curricula, limiting cross-disciplinary work. The report also provided a series of recommendations to address these barriers, including establishing translational behavioral science research as a priority funding area for NIMH, develop a strategy for its systematic development, and develop innovative approaches for supporting translational research in the behavioral sciences. This report was followed by additional workshops and publications that contained similar recommendations (Muehrer et al., 2002).

The 1990's and early 2000's saw a number of efforts to stimulate basic-to-clinical behavioral translation, most notably led by NIDA and its spearheading of several funding opportunity announcements (FOAs) aimed at translating basic cognitive, behavioral and social science research into more effective behavioral interventions for addictive disorders. In particular, Dr. Lisa Onken and her team in the Behavioral Therapies Development branch of NIDA were responsible for stimulating cutting-edge translational science through workshops and FOAs that explored the potential for basic behavioral and neuroscience research to inform clinical research on drug abuse and mental health disorders. These efforts continue to the 
present day with FOAs sponsored by NIDA and NIAAA that support pilot and feasibility studies for the development and testing of novel prevention interventions in the area of drug and alcohol use/abuse (https://grants.nih.gov/ grants/guide/pa-files/PA-18-067.html) and NIMH-funded RFA programs designed to support the efficient pilot testing of novel psychosocial therapeutic and preventive interventions for mental disorders in adults and children using an experimental therapeutics approach (https://grants.nih.gov/ grants/guide/rfa-files/RFA-MH-18-704.html).

Several types of NIH funding mechanisms are especially appropriate and often used to support investigator-initiated early-phase translational research. The R21 mechanism is often used for innovative, exploratory/developmental research projects (e.g., https://grants.nih.gov/grants/guide/ pa-files/PAR-18-018.html). The Exploratory/Developmental Phased Innovation grant mechanism (R21/R33) combines a 2 year exploratory, planning and/or feasibility phase followed by transition to a 3-year replication and/or efficacy testing phase (e.g., see https://grants.nih.gov/ grants/guide/pa-files/PAR-18-086.html and https://grants. nih.gov/grants/guide/pa-files/PAR-18-307.html). The P20 Exploratory Grant has also been used effectively by some Institutes to encourage early-phase animal and human behavioral translation research (as in the Exploratory Centers for Translation on the Clinical Neurobiology of Drug Addiction-http://grants2.nih.gov/grants/guide/rfafiles/RFA-DA-09-012.html).

A number of Institute-initiated programs have been critical in promoting early-phase translational behavioral research using a variety of grant and contract mechanisms. Selected examples are provided in Table 2.

Along with the funding of individual studies and programs of research that have served to advance early-phase behavioral translational science, NIH has served an important role in stimulating the creation of several frameworks and/or methods that can be used to achieve a more systematic approach to behavioral intervention development. These include the Stage Model of Treatment Development (Rounsaville et al., 2006; Onken et al., 2014); the ORBIT model for developing behavioral treatments for chronic diseases (Czajkowski et al., 2015); and the NIH Science of Behavior Change Program's mechanistically-focused experimental medicine approach (Nielsen et al., 2018).

\section{Dissemination and implementation research}

Although there have been important advances in clinical trials of behavioral interventions over the last 40 years, translating the findings from well-controlled trials of research participants to real-world contexts involving complex patients in everyday settings has been tackled less frequently in behavioral medicine. Because clinical trials to establish efficacy and, to lesser extent effectiveness, enroll participants who are well-characterized in a controlled research environment, additional efforts to understand how to effectively translate evidence-based interventions into clinical practice and communities is required. Dissemination research - which studies how information and materials related to interventions is distributed to a targeted health-related audience-and implementation researchthe investigation of strategies to increase the update of interventions to improve clinical practice and patient outcomes-address the development, testing, and effectiveness of these translational strategies. Both aim to integrate evidence-based practices into routine clinical practice and everyday use.

Across all areas of medicine, it has been estimated that it takes an average of 17 years before only $14 \%$ of research findings lead to widespread changes in care (Balas \& Boren, 2000). This inefficiency results in substantial human and financial costs, and dissemination and implementation (D\&I) research aims to reduce that timeframe so that evidence-based practices are more effectively and more frequently taken up to improve health. Although a reasonably new area of research, this complex field of study to investigate strategies for improving our ability to integrate evidence-based practices into routine clinical practice and everyday use is increasingly being employed by behavioral scientists to ultimately improve population health.

Implementation strategies focus on behaviors by patients, providers, families, healthcare systems, and/or communities to identify the barriers to implementing evidence-based interventions and identify potential strategies or adaptations necessary to address these barriers. This work is strongly informed by contextual factors such as environmental factors, cultural influences, economic and other social determinants, and community resources. Many successful implementation efforts involve tailoring interventions to relevant contextual factors, making this essential research in understanding how to best reach rural and other underserved populations and individuals residing in developing areas of the world. Important metrics for successful implementation include factors such as uptake, acceptability, reach or spread, sustainability, and cost or burden.

$\mathrm{NIH}$ has had a strong interest in fostering dissemination and implementation efforts over about the last 20 years, by issuing a variety of funding opportunities and programs for conducting research in this space (see https://grants.nih. gov/grants/guide/pa-files/PAR-18-007.html for the most recent example), sponsoring conferences and workshops, and, in more recent years, developing and sponsoring training opportunities in dissemination and implementation 
Table 2 Examples of institute-initiated initiatives in early-phase translational behavioral research

\begin{tabular}{|c|c|c|}
\hline Initiative & Description & Website/url \\
\hline Work, family and health network & $\begin{array}{l}\text { NICHD network supporting research across the translational } \\
\text { spectrum-from pilot studies through full-scale } \\
\text { randomized trials and implementation studies in } \\
\text { workplace settings-focused on workplace structures, } \\
\text { systems and policies that lead to better individual and } \\
\text { family well-being and health }\end{array}$ & $\begin{array}{l}\text { http://grants.nih.gov/grants/ } \\
\text { guide/rfa-files/RFA-HD- } \\
\text { 07-101.html }\end{array}$ \\
\hline $\begin{array}{l}\text { Translational behavioral science research consortia } \\
\quad(\text { TBSRC) }\end{array}$ & $\begin{array}{l}\text { Broad agency announcement (BAA) that funded two 5-year } \\
\text { contracts by the National Heart, Lung, and Blood Institute } \\
\text { (NHLBI) in } 2002 \text { to translate basic behavioral science } \\
\text { theory and findings into interventions for heart, lung, and } \\
\text { blood diseases and disorders }\end{array}$ & $\begin{array}{l}\text { http://grants.nih.gov/grants/ } \\
\text { guide/notice-files/NOT- } \\
\text { HL-02-005.html }\end{array}$ \\
\hline $\begin{array}{l}\text { Transdisciplinary tobacco use research centers } \\
\text { (TTURC) program }\end{array}$ & $\begin{array}{l}\text { 10-year initiative funded by NCI in partnership with NIDA } \\
\text { and the National Institute on Alcohol Abuse and } \\
\text { Alcoholism (NIAAA) in } 2004 \text { to support basic and } \\
\text { applied research on tobacco use }\end{array}$ & $\begin{array}{l}\text { http://cancercontrol.cancer. } \\
\text { gov/brp/tcrb/tturc/about. } \\
\text { html }\end{array}$ \\
\hline $\begin{array}{l}\text { Transdisciplinary research on energetics and cancer } \\
\text { (TREC) program }\end{array}$ & $\begin{array}{l}\text { 10-year initiative funded by NCI in } 2006 \text { that connected } \\
\text { basic biological and behavioral scientists with applied } \\
\text { researchers to identify and test interventions to reduce the } \\
\text { burden of obesity }\end{array}$ & $\begin{array}{l}\text { https://cancercontrol.cancer. } \\
\text { gov/brp/hbrb/trec/index. } \\
\text { html }\end{array}$ \\
\hline $\begin{array}{l}\text { Obesity related behavioral intervention trials } \\
\text { (ORBIT) consortium }\end{array}$ & $\begin{array}{l}\text { Cooperative agreement (U01) funded in } 2008 \text { by the NHLBI } \\
\text { in partnership with NCI, NICHD, NIDDK and OBSSR to } \\
\text { translate findings from basic research on human behavior } \\
\text { to develop more effective interventions for reducing } \\
\text { obesity and improving obesity-related health behaviors }\end{array}$ & $\begin{array}{l}\text { http://grants.nih.gov/grants/ } \\
\text { guide/rfa-files/RFA-HL- } \\
\text { 08-013.html }\end{array}$ \\
\hline $\begin{array}{l}\text { Translating basic behavioral and social science } \\
\text { research discoveries into interventions to improve } \\
\text { health-related behaviors }\end{array}$ & $\begin{array}{l}\text { Program announcement (PA) developed in } 2011 \text { by OBSSR } \\
\text { which funded } 17 \text { grants across several Institutes focusing } \\
\text { on translation of basic behavioral science findings into } \\
\text { preventive and therapeutic interventions for diseases and } \\
\text { disorders ranging from hypertension, cardiovascular } \\
\text { disease and cancer to obesity and diabetes }\end{array}$ & $\begin{array}{l}\text { http://grants.mh.gov/grants/ } \\
\text { guide/pa-files/PA-11-063. } \\
\text { html }\end{array}$ \\
\hline Roybal centers for translational research on aging & $\begin{array}{l}\text { Through the Roybal Centers, NIA supports research to } \\
\text { (develop and test new and innovative ideas for early stage } \\
\text { and late stage translation of basic behavioral and social } \\
\text { research findings about established or hypothesized } \\
\text { mechanisms of action, at the individual or population } \\
\text { level, into programs and practices that will improve the } \\
\text { lives of older people and the capacity of institutions to } \\
\text { adapt to societal aging }\end{array}$ & $\begin{array}{l}\text { https://grants.nih.gov/ } \\
\text { grants/guide/rfa-files/rfa- } \\
\text { ag-19-006.html }\end{array}$ \\
\hline Science of behavior change (SOBC) initiative & $\begin{array}{l}\text { The NIH Office of the Director supports this Common Fund } \\
\text { initiative which funds basic behavioral research to } \\
\text { identify common mechanisms underlying multiple } \\
\text { diseases and health problems and translational research to } \\
\text { develop and test interventions to alter health-related } \\
\text { behaviors based on an experimental medicine approach to } \\
\text { behavior change research }\end{array}$ & $\begin{array}{l}\text { https://commonfund.nih. } \\
\text { gov/behaviorchange/ } \\
\text { index }\end{array}$ \\
\hline
\end{tabular}

research. NIMH released its first program announcement on dissemination research in mental health in 1999 (see https:// grants.nih.gov/grants/guide/pa-files/PA-99-068.html), followed by additional funding opportunity announcements in 2002 and a 2004 "Advancing the Science of Implementation" Workshop (Chambers, 2008). These activities were closely paralleled by the NCI, whose dissemination and implementation research initiatives included funding a series of diffusion and dissemination grant supplements in 2002 and development of the "Cancer Control P.L.A.N.E.T." website and initiative in 2003 (https://cancercontrolplanet. cancer.gov/planet/). In 2014, NHLBI created the Center for Translation Research and Implementation Science (CTRIS) specifically to encourage and support research to identify effective strategies for ensuring successful integration of evidence-based interventions into healthcare, school, and community settings.

Beginning in 2005, D\&I activities and funding announcements were becoming more widespread across the NIH, with eight Institutes, Centers and Offices (ICOs) 
signing onto dissemination and implementation research program announcements. The first NIH conference on dissemination and implementation research was held on the NIH campus in 2007; by 2012 (the fifth NIH D\&I conference), over 1200 registrants enrolled to hear talks spanning the spectrum of D\&I research, and the annual meeting, now in its 11 th year, continues to grow each year. In 200912 ICOs and OBSSR had signed on to reissue the program announcements and in 201617 ICOs + OBSSR had signed onto the D\&I program announcements.

In 2010, the Center for Scientific Progress developed a standing review committee-the Dissemination and Implementation Research in Health (DIRH) Study Section-and in 2011, the first Training Institute for Dissemination and Implementation Research was held, with support from the Office of Behavioral and Social Sciences Research (OBSSR) in the Office of the Director at NIH. The 8-year-old program continues to train young as well as established researchers from around the world to ensure that resources to develop and test interventions for efficacy are not wasted because of a lack of knowledge regarding how to implement treatments in real-world settings.

NIH staff have been instrumental in the application of evidence-based behavioral strategies to policy and medical practice, a key dissemination and implementation activity. The NIH Office of Disease Prevention (ODP) serves as the NIH's liaison to the United States Preventive Services Task Force (USPSTF), which reviews the literature and provides recommendations about clinical preventive services. Guidance from the USPSTF often centers on the impact of behavioral counseling, based on evidence largely gleaned from NIH-supported research.

Ultimately, behavioral scientists have had an important role in developing the interdisciplinary science of dissemination and implementation, and the NIH has made significant efforts over several decades to support dissemination and implementation science to help close the "research to practice gap."

\section{Advances in measurement: behavioral medicine and the science of assessment}

"The grandest discoveries have been but the rewards of accurate measurement" (Thomson, 1871), and the behavioral and social sciences are entering a period of advances in accurate measurement that may lead to breakthroughs in our understanding of behavior and social systems. Technological advances of smartphones, wearables, and homebased sensors (Cornet \& Holden, 2018) and the increasing access and use of administrative and commercial data from the daily interactions of individuals with technology (Pentland et al., 2009) have revolutionized direct obser- vation from a labor and resource intensive measurement approach to an automated, predominately passive, and increasingly reliable and accurate measurement approach. Even the staple of behavioral and social sciences research, survey items and questionnaires, have been greatly improved with advances in modern psychometrics and Ecological Momentary Assessment (EMA). The contributions of NIH to these efforts is extensive, and the following are but a few key efforts of the NIH that contributed to advances in measurement.

\section{Mobile, wireless, and sensors}

The same year as the release of the iPhone, 2007, the NIH initiated the Gene, Environment and Health Initiative (GEI; $\mathrm{NIH}, 2007)$. Alongside research on innovative genomic tools, the GEI included research on innovative environmental measurement tools including environmental sensors for personal exposure assessment, biological indicators of environmental stress, improved measures of diet and physical activity, and tools to measure exposure to psychosocial stress and addictive substances. The GEI was the crucible for many subsequent NIH-supported efforts in the last decade including the Mobile Data to Knowledge project of the Big Data to Knowledge Initiative (Kumar et al., 2015), the annual mHealth Training Institute, and a number of NIH initiatives including Mobilizing Research (RFAOD-15-129) and Intensive Longitudinal Analysis of Health Behaviors (RFA-OD-17-004).

\section{Behavioral informatics}

Sources of digital data relevant to understanding behavior in context include data from cell phones, social media, internet searches, and various administrative databases. There have been numerous NIH FOAs to encourage the uses of these data for behavioral and social sciences research, and NCI's Health Communication and Informatics Research Branch has spearheaded many NIH efforts in behavioral informatics and social media [e.g., see "Innovative Approaches to Studying Cancer Communication in the New Media Environment" (PAR-18-638) and the biannual Health Information National Trends Survey (HINTS) which captures the US public's health attitudes, pursuit of health information, and experiences exchanging health information with providers (Hesse et al., 2017)]. One increasing source of health data has come from the electronic health record (EHR). Recognizing this increasing source of health research data and the dearth of social and behavioral aspects of health contained in the EHR, OBSSR and NCI, along with other federal partners, supported an Institute of Medicine report on Capturing Social and Behavioral Domains and Measures in Electronic 
Health Records (IOM, 2014). This report identified key domains and measures for inclusion in the EHR that would be useful for the patient-provider decision making, for population health monitoring and policymaking, and for health research. The subsequent efforts by the Office of the National Coordinator for Health Information Technology (ONC) and population health provisions within the Patient Protection and Affordable Care Act (ACA); have ensured that social and behavioral domains are more integrated into the EHR and the healthcare delivery system.

\section{Modern psychometrics and EMA}

Among the first round of NIH Roadmap (now Common Fund) initiatives in 2004 was the Patient Reported Outcomes Measurement Information System (PROMIS) with the goal of leveraging recent advances in information technology, modern psychometrics, and qualitative item research methods to develop item banks measuring various domains of physical, mental, and social health applicable across a wide range of health research (Cella et al., 2007). A less well understood but equally important goal of the PROMIS Initiative was to standardize the metric or scale on which any patient-reported measure of a given domain could be expressed, greatly facilitating data sharing and harmonization (Choi et al., 2014). Two years after the initiation of PROMIS, in 2006, the NIH Blueprint for Neuroscience Research initiated the NIH Toolbox effort which utilized similar measurement development principles as PROMIS to develop and test performance measures for sensory, motoric, cognitive, and emotional domains (Gershon et al., 2010). Along with two other measurement systems, NeuroQoL and ASCQ-Me, that were developed similarly using item response theory (IRT), these measurement systems are available at www.healthmeasures. net.

In addition to supporting advances in the development of self-report tools, the NIH has also supported the development of computer platforms for administering and scoring these tools. The healthmeasures.net tools all utilize computer adaptive testing which not only automates administration and scoring but also leverages IRT to administer items more flexibly and efficiently (Bass et al., 2015). Another advance in self-report administration has been the use of EMA (Shiffman et al., 2008). In 2003, the NCI led a meeting on the Science of Real-time Data Capture which led to a subsequent publication by the same name (Stone et al., 2007). At that time, EMA had begun to be used for research purposes, primarily on PDAs or combinations of pagers, text messages, and/or paper diaries, and the field needed guidance on best practices for EMA based on the science underlying real-time data capture. This meeting and subsequent publications helped prepare the field for the proliferation of EMA research use resulting from the advent of the smartphone.

\section{Conclusion}

This review illustrates the important role played by NIHsupported behavioral and social sciences research in the advances made in the science and practice of behavioral medicine as a field over the past 40 years. Behavioral medicine research has matured into an established and respected part of the NIH research portfolio, but the path to its current state at the NIH has not always been straightforward nor well-supported, and NIH staff in the behavioral and social sciences have addressed numerous challenges and impediments in the past 40 years to continue the progress in behavioral medicine at the NIH. The $\mathrm{NIH}$ always has been a primarily biomedical institution, with resulting pressures to emphasize biological causes of diseases and their treatment. As illustrated by its 40 year history, for behavioral medicine research to flourish in this environment requires adopting methods and approaches that are persuasive to the biomedical community, integrating behavioral and social science questions within larger biomedical initiatives, encouraging innovative, rigorous, and compelling research from the behavioral and social sciences research community, communicating this research in the context of its public health relevance, advocating vigorously for critical research needs, and being opportunistic and persistent in supporting behavioral and social sciences research relevant to the health of the nation. The current state of behavioral medicine at the NIH could not have been achieved without these efforts, not only from NIH leaders in the field, but also from the many NIH staff who steward behavioral and social science research portfolios, from the behavioral medicine research community, and from various stakeholders who value the importance of this research for improving health and who advocate for its support.

That behavioral medicine research is established and respected at the NIH is an important achievement; however, gains over the past 40 years can deteriorate quickly without continued efforts to advance behavioral and social sciences research and to apply this research to pressing public health needs. For example, the increasing rates of obesity, particularly in children, threatens to roll back years of progress in preventing and treating chronic diseases such as cardiovascular disease, cancer and diabetes (https:// www.cdc.gov/obesity/data/adult.html). To address this problem, the NIH has developed a variety of initiatives and funded many investigators in both the biomedical and behavioral sciences to investigate the causes and consequences of obesity and to develop effective interventions. 
New NIH programs of research are underway to increase our understanding of obesity and its related biological, behavioral, psychosocial and environmental correlates, potentially leading to improved preventive and therapeutic interventions and ultimately, to reductions in obesity and its adverse consequences. An example of a new approach to this long-standing health problem is the Accumulating Data to Optimally Predict obesity Treatment (ADOPT) Core Measures project (MacLean et al., 2018) which seeks to identify factors predicting weight loss and its maintenance to more precisely tailor weight loss interventions and improve their sustainability. The NIH Obesity Task Force, which is charged with stimulating and coordinating obesity-related activities across the NIH (see https:// obesityresearch.nih.gov/about/), disseminates up-to-date information about current funding opportunities and ongoing programs of research (for a listing of current obesity-related initiatives and activities see https:// obesityresearch.nih.gov/funding/funding.aspx).

Another critical public health issue is continued widening of health disparities. While considerable research has documented the nature and extent of these disparities, research that targets malleable social mechanisms and tests interventions to reduce these disparities is lagging. BSSR initiatives are playing and will continue to play a key role in addressing disparities in health based on race/ethnicity, gender, socioeconomic status, geographic location, sexual minority status and other characteristics. NIH Institutes, Centers and Offices, including the National Institute on Minority Health and Health Disparities (NIMHD), the Office of Research on Women's Health (ORWH) are charged with supporting research and other activities to elucidate the causes, consequences, and potential remediating strategies for these and other disparities in health. Examples of initiatives include the NIMHD Transdisciplinary Collaborative Centers (TCC) for Health Disparities Research on Chronic Disease Prevention program (https:// www.nih.gov/news-events/news-releases/nih-establishesnew-research-program-address-health-disparities-chronicdiseases) which is supporting two centers charged with developing, implementing and disseminating communitybased, multilevel interventions for chronic diseases (CVD, diabetes, cancer).

Opioid Use Disorder (OUD) and overdoses are highly salient and pressing public health crises receiving increased attention at the NIH. With additional funding from Congress beginning in FY18, the NIH is doubling its investment in research to address the opioid crisis via the Helping to End Addiction Long-term (HEAL) Initiative ((https:// www.nih.gov/research-training/medical-research-initiatives/ heal-initiative). Following three HEAL Initiative workshops focusing predominately on biomedical research needs (e.g., medication development for new OUD treatments or non- addictive pain management), the OBSSR worked with NIH leadership and the HEAL Initiative to hold a workshop on "Contributions of Social and Behavioral Research in Addressing the Opioid Crisis" (https://www.nih.gov/ heal-initiative/full-summary-contributions-social-behavioralresearch-addressing-opioid-crisis). This meeting specified key actionable social and behavioral science findings that can be brought to bear immediately to address the opioid crisis, and identified critical short-term, as well as potential mid-term and longer-term research priorities that have the potential to improve the opioid crisis response. The results from this meeting are informing the development of funding announcements that will address the social and behavioral as well as the biomedical research needs to address this critical public health crisis.

Through these and other initiatives, behavioral medicine research at the NIH continues to contribute to advancing the science of behavior while offering solutions to significant clinical and public health problems, demonstrating its critical importance both within the NIH and in the public health arena.

Acknowledgements The authors wish to acknowledge the helpful contributions to this article made by Michele Bloch, David Chambers, Elizabeth Neilson, Mark Parascondola and Michael Stirratt.

\section{Compliance with ethical standards}

Conflict of interest Susan M. Czajkowski, William T. Riley, Catherine M. Stoney, William M. P. Klein, Robert T. Croyle declare that they have no conflict of interest.

Ethical approval This article does not contain any studies with human participants or animals performed by any of the authors.

Human and animal rights and Informed consent All procedures followed were in accordance with ethical standards of the responsible committee on human experimentation (institutional and national) and with the Helsinki Declaration of 1975, as revised in 2000. Informed consent was obtained from all patients for being included in the study.

\section{References}

Abrams, D. B. (2006). Applying transdisciplinary research strategies to understanding and eliminating health disparities. Health Education and Behavior, 33, 515-531.

Academy of Behavioral Medicine Research Steering Committee minutes, Institute of Medicine, Washington, D.C. April 10, 11, 1978. Available from ABMR website: http://storage.cloversites. com/academyofbehavioralmedicineresearch/documents/IOM\% 20minutes\%20creating\%20ABMR\%20041278.pdf. Accessed 24 August 2018.

Anderson, N. B. (1997). Integrating behavioral and social sciences research at the National Institutes of Health, U.S.A. Social Science and Medicine, 44, 1069-1071.

Balas, E. A., \& Boren, S. A. (2000). Yearbook of medical informatics: Managing clinical knowledge for health care improvement. Stuttgart: Schattauer Verlagsgesellschaft $\mathrm{mbH}$. 
Bass, M., Morris, S., \& Neapolitan, R. (2015). Utilizing multidimensional computer adaptive testing to mitigate burden with patient reported outcomes. AMAI Annual Symposium Proceedings, 5, 320-328.

Berg, C. J., Fong, G. T., Thrasher, J. F., et al. (2018). The impact and relevance of tobacco control research in low-and middle-income countries globally and to the US. Addictive Behaviors, 87, $162-168$.

Berkman, L. F., Leo-Summers, L., \& Horwitz, R. I. (1992). Emotional support and survival after myocardial infarction: A prospective, population-based study of the elderly. Annals of Internal Medicine, 117, 1003-1009.

Berkman, L. F., et al. (2003). Effects of treating depression and low perceived social support on clinical events after myocardial infarction: The Enhancing Recovery in Coronary Heart Disease Patients (ENRICHD) randomized trial. JAMA, 289, 3106-3116.

Bradley, S. M., \& Rumsfeld, J. S. (2015). Depression and cardiovascular disease. Trends in Cardiovascular Medicine, 25, 614-622.

Cella, D., et al. (2007). The patient-reported outcomes measurement information system (PROMIS): Progress of an NIH Roadmap cooperative group during its first two years. Medical Care, 45, S3-S11.

Centers for Medicare and Medicaid Services Website. (2017) Medicare Diabetes Prevention Program (MDPP) expanded model. https://innovation.cms.gov/initiatives/medicare-diabetesprevention-program. Accessed 20 July 2018.

Chambers, D. A. (2008). Advancing the science of implementation: A workshop summary. Administration and Policy in Mental Health and Mental Health Services Research, 35, 3-10.

Choi, S. W., Shalet, B., Cook, K. F., \& Cella, D. (2014). Establishing a common metric for depressive symptoms: Linking the BDI-II, CES-D, and PHQ-9 to PROMIS depression. Psychological Assessment, 26, 513-527. https://doi.org/10.1037/a0035768

Collins, F. S., et al. (2016). Basic science: Bedrock of progress. Science, 351, 1405. https://doi.org/10.1126/science.351.6280. 1405-a

Collins, L. M., Murphy, S. A., \& Strecher, V. (2007). The Multiphase Optimization Strategy (MOST) and the sequential multiple assignment randomized trial (SMART): New methods for more potent eHealth interventions. American Journal of Preventive Medicine, 32, S112-S118.

Cornet, V. P., \& Holden, R. J. (2018). Systematic review of smartphone-based passive sensing for health and wellbeing. Journal of Biomedical Informatics, 77, 120-132.

Czajkowski, S. M., Lynch, M. R., Hall, K. L., Stipelman, B. A., Haverkos, L., Perl, H., et al. (2016). Transdisciplinary translational behavioral (TDTB) research: Opportunities, barriers, and innovations. Translational Behavioral Medicine, 6, 32-43.

Czajkowski, S. M., Powell, L. H., Adler, N., et al. (2015). From ideas to efficacy: The ORBIT model for developing behavioral treatments for chronic diseases. Health Psychology, 34, 971-982.

Davidson, K. W., Bigger, J. T., Burg, M. M., et al. (2013). Centralized, stepped, patient preference-based treatment for patients with post-acute coronary syndrome depression: CODIACS vanguard randomized controlled trial. JAMA Internal Medicine, 173, 997-1004.

Department of Health and Human Services, National Institutes of Health, National Institute of Mental Health. (2000). Translating behavioral science into action: Report of the National Advisory Mental Health Council's behavioral science workgroup. Available at: https://www.nimh.nih.gov/about/advisory-boards-andgroups/namhc/reports/translating-behavioral-science-into-actionreport-of-the-national-advisory-mental-health-council-behavioralscience-workgroup.shtml. Accessed 24 August 2018.
Diabetes Prevention Program Research Group. (2002). Reduction in the incidence of type 2 diabetes with lifestyle intervention or metformin. New England Journal of Medicine, 346, 393-403.

Editorial. (2004). Lost in clinical translation. Nature Medicine, 10, 879.

Faster Cures. (2011). Back to basics: HIV/AIDS activism as a model for catalyzing change. http://www.fastercures.org/assets/ Uploads/PDF/Back2BasicsFinal.pdf. Accessed 24 August 2018.

Fishbein, D. H., Ridenour, T. A., Stahl, M., \& Sussman, S. (2016). The full translational spectrum of prevention science: Facilitating the transfer of knowledge to practices and policies that prevent behavioral health problems. Translational Behavioral Medicine, 6, 5-16.

Fort, D. G., Herr, T. M., Shaw, P. L., Gutzman, K. E., \& Starren, J. B. (2017). Mapping the evolving definitions of translational research. Journal of Clinical and Translational Science, 1, 60-66. https://doi.org/10.1017/cts.2016.10

Frasure-Smith, N., Lespérance, F., \& Talajic, M. (1993). Depression following myocardial infarction: impact on 6-month survival. JAMA, 270, 1819-1825.

Gershon, R. C., Cella, D., Fox, N. A., Havlik, R. J., Hendrie, H. C., \& Wagster, M. V. (2010). Assessment of neurological and behavioural function: The NIH toolbox. Lancet Neurology, 9, 138-139. https://doi.org/10.1016/S1474-4422(09)70335-7

Gillman, M. W., \& Blaisdell, C. J. (2018). Environmental influences of child health outcomes, a research program of the National Institutes of Health. Current Opinions in Pediatrics, 30, 260-262.

Ginexi, E. M., \& Vollinger, R. E. (2016). National Cancer Institute's leadership role in promoting state and community tobacco control research. Tobacco Control, 25, i4-i5.

Hesse, B. W., Greenberg, A. J., Peterson, E. B., \& Chou, W. Y. S. (2017). The health information national trends survey (HINTS): A resource for consumer engagement and health communication research. Information Services \& Use, 37, 205-218.

Holden, C. (2004). NIMH takes a new tack, upsetting behavioral researchers. Science, 306, 602. https://doi.org/10.1126/science. 306.5696.602

Holford, T. R., Meza, R., Warner, K. E., et al. (2014). Tobacco control and the reduction in smoking-related premature deaths in the United States, 1964-2012. JAMA, 311, 164-171.

IOM (Institute of Medicine). (2014). Capturing social and behavioral domains and measures in electronic health records: Phase 2. Washington: The National Academies Press.

Kaphingst, K. A., McBride, C. M., Wade, C., Alford, S. H., Reid, R., Larson, E., et al. (2012). Patients' understanding of and responses to multiplex genetic susceptibility test results. Genetics in Medicine, 14, 681.

Kaplan, R. M., Johnson, S. B., \& Kobor, P. C. (2017). NIH behavioral and social sciences research support: 1980-2016. American Psychologist, 72, 808-821.

Keefe, F. J. (2011). Behavioral medicine: A voyage to the future. Annals of Behavioral Medicine, 41, 141-151.

Khoury, M. J., Gwinn, M., Yoon, P. W., Dowling, N., Moore, C. A., Bradley, L. (2007). The continuum of translation research in genomic medicine: How can we accelerate the appropriate integration of human genome discoveries into health care and disease prevention? Genetics in Medicine, 9, 665-674.

Kraut, A. G. (2004). The Importance of Basic Behavioral Science to Health. APS Observer, June 23, 2004. https://www.psychological science.org/observer/the-importance-of-basic-behavioral-scienceto-health.

Kumar, S., et al. (2015). Centers of excellence for mobile sensor datato-knowledge (MD2 K). Journal of the American Medical Informatics Association, 22, 1137-1142. https://doi.org/10. 1093/jamia/ocv056 
Lespérance, F., Frasure-Smith, N., Talajic, M., \& Bourassa, M. G. (2002). Five-year risk of cardiac mortality in relation to initial severity and one-year changes in depression symptoms after myocardial infarction. Circulation, 105, 1049-1053.

Mabry, P. L., \& Kaplan, R. M. (2013). Systems science: A good investment for the public's health. Health Education and Behavior, 40, 9S-12S. https://doi.org/10.1177/1090198113503469

Mabry, P. L., Olster, D. H., Morgan, G. D., \& Abrams, D. B. (2008). Interdisciplinarity and systems science to improve population health: A view from the NIH office of behavioral and social sciences research. American Journal of Preventive Medicine, 35, S211-S224.

MacLean, P. S., Rothman, A. J., Nicastro, H. L., Czajkowski, S. M., Agurs-Collins, T., et al. (2018). The accumulating data to optimally predict obesity treatment (ADOPT) core measures project: Rationale and approach. Obesity, 26, S6-S15.

Mechanic, D. (2018). Biographical memoirs: Matilda W. Riley 19112004. National Academy of Sciences. http://www.nasonline.org/ publications/biographical-memoirs/memoir-pdfs/riley_matilda_ white.pdf. Accessed 24 August 2018.

Meissner, H. I., Glasgow, R. E., Vinson, C. A., Chambers, D., Brownson, R. C., et al. (2013). The US training institute for dissemination and implementation research in health. Implementation Science, 8, 12. https://doi.org/10.1186/1748-5908-8-12

Mental Health Matters. (2009). HIV-AIDS research at the National Institute of Mental Health. https://mental-health-matters.com/hivaids-research-at-the-national-institute-of-mental-health/. Accessed 24 August 2018.

Meslin, E. M., Thomson, E. J., \& Boyer, J. T. (1997). The ethical, legal, and social implications research program at the national human genome research institute. Kennedy Institute of Ethics Journal, 7, 291-298.

Muehrer, P. R., Salovey, P., Afifi, A. A., Coyne, J. C., et al. (2002). Overcoming barriers to collaboration between basic behavioral scientists and public health scientists in research on mental disorders. Journal of Clinical Psychology in Medical Settings, 9, 253-265.

National Cancer Institute (NCI). (1995). Monograph 6 NCI monograph 6: Community-based interventions for smokers: The COMMIT Field Experience. http://cancercontrol.cancer.gov/ brp/tcrb/monographs/6/index.html. Accessed 24 August 2018.

National Cancer Institute (NCI). (2005). Monograph 16: ASSISTshaping the future of tobacco prevention and control: Implementation of American stop smoking intervention study for cancer prevention. http://cancercontrol.cancer.gov/brp/tcrb/ monographs/16/index.html. Accessed 24 August 2018.

National Cancer Institute (NCI). (2006). Monograph 17: Evaluating ASSIST-A blueprint for understanding state-level tobacco control: Evaluation of American stop smoking intervention study for cancer prevention. http://cancercontrol.cancer.gov/brp/ tcrb/monographs/17/index.html

National Cancer Institute (NCI). (2012). Tobacco research initiative for state and community interventions (TRISCI) website. http:// cancercontrol.cancer.gov/brp/tcrb/scrfa.html. Accessed 26 April 2015.

National Institutes of Health (NIH). (2004). Report of the working group of the NIH advisory committee to the director on research opportunities in the basic behavioral and social sciences. https:// obssr.od.nih.gov/wp-content/uploads/2016/07/Basic-Beh-Report_ complete.pdf. Accessed 24 August 2018.

National Institutes of Health (NIH). (2007). https://www.nih.gov/ news-events/news-releases/genes-environment-health-initiativeinvests-genetic-studies-environmental-monitoring-technologies. Accessed 24 August 2018.
National Institutes of Health (NIH) (2014). BRAIN 2025: A scientific vision. https://www.braininitiative.nih.gov/pdf/BRAIN2025_ 508C.pdf. Accessed 24 August 2018.

National Research Council. (1982). Health and behavior: Frontiers of research in the biobehavioral sciences. Washington: The National Academies Press. https://doi.org/10.17226/19528

Nielsen, L., Riddle, M., King, J. W., Aklin, W. M., Chen, W., et al. (2018). The NIH science of behavior change program: Transforming the science through a focus on mechanisms of change. Behavior Research and Therapy, 101, 3-11.

Nilsen, W., Riley, W. T., \& Heetderks, W. (2013). News from the NIH: Using mobile and wireless technologies to improve health. Translational Behavioral Medicine, 3, 227-228.

Office of Behavioral and Social Sciences Research (OBSSR), Office of Behavioral and Social Sciences Research Strategic Plan 2017-2021. https://obssr.od.nih.gov/wp-content/uploads/2016/ 12/OBSSR-SP-2017-2021.pdf. Accessed 24 August 2018.

Office of Smoking and Health, Office of the Surgeon General. (1988). The health consequences of smoking: Nicotine addiction: A report of the surgeon general. The full report is available here: https://profiles.nlm.nih.gov/NN/B/B/Z/D/. Accessed 24 August 2018.

Office on Smoking and Health, National Center for Chronic Disease Prevention and Health Promotion, Trends in Current Cigarette Smoking Among High School Students and Adults, U.S., 1965-2014. http://www.cdc.gov/tobacco/data_statistics/tables/ trends/cig_smoking/index.htm. Accessed 24 August 2018.

Onken, L. S., Carroll, K. M., Shoham, V., Cuthbert, B. N., \& Riddle, M. (2014). Reenvisioning clinical science: Unifying the discipline to improve the public health. Clinical Psychology: Science and Practice, 2, 22-34.

Parascandola, M. (2001). Cigarettes and the US public health service in the 1950s. American Journal of Public Health, 91, 196-205.

Parascondola, M. (2011). Tobacco harm reduction and the evolution of nicotine dependence. American Journal of Public Health, 101, 632-641.

Pentland, A., Lazar, D., Brewer, D., \& Heibeck, T. (2009). Using reality mining to improve public health and medicine. In $\mathrm{R}$. G. Bushko (Ed.), Strategy for the future of health (pp. 93-102). Amsterdam: IOS Press.

Rigotti, N. A., \& Stoney, C. M. (2016). CHARTing the future course of tobacco-cessation interventions for hospitalized smokers. American Journal of Preventive Medicine, 51, 549-550.

Riley, W. T. (2017a). Basic and applied behavioural and social sciences at the NIH. Nature Human Behaviour, 1, 0023.

Riley, W. T. (2017b). Behavioral and social sciences at the National Institutes of Health: Methods, measures, and data infrastructures as a scientific priority. Health Psychology, 36, 5-7. https://doi. org/10.1037/hea0000464

Riley, W. T. (2017c). Behavioral and social sciences at the National Institutes of Health: Adoption of research findings in health research and practice as a scientific priority. Translational Behavioral Medicine, 7, 380-384.

Riley, W. T., \& Blizinsky, K. D. (2017). Implications of the 21st century cures act for the behavioral and social sciences at the national institutes of health. Health Education and Behavior, 44, 356-359. https://doi.org/10.1177/1090198117707964

Riley, W. T., Nilsen, W. J., Manolio, T. A., Masys, D. R., \& Lauer, M. (2015). News from the NIH: Potential contributions of the behavioral and social sciences to the precision medicine initiative. Translational Behavioral Medicine, 5, 243-246. https://doi.org/10.1007/s13142-015-0320-5

Riley, W. T., Stevens, V. J., Zhu, S. H., Morgan, G., \& Grossman, D. (2012). Overview of the consortium of hospitals advancing research on tobacco (CHART). Trials, 13, 122. 
Rounsaville, B. J., Carroll, K. M., \& Onken, L. S. (2006). A stage model of behavioral therapies research: Getting started and moving on from stage I. Clinical Psychology: Science and Practice, 8, 133-142.

Schmitt, C. L., Lee, Y. O., Curry, L. E., et al. (2014). Research support for effective state and community tobacco control program response to electronic nicotine delivery systems. Tobacco Control, 23, 54-57.

Schwartz, G. E., \& Weiss, S. M. (1978a). Yale conference on behavioral medicine: A proposed definition and statement of goals. Journal of Behavioral Medicine, 1, 3-12.

Schwartz, G. E., \& Weiss, S. M. (1978b). Behavioral medicine revisited: An amended definition. Journal of Behavioral Medicine, 1, 249.

Shiffman, S., Stone, A. A., \& Hufford, M. R. (2008). Ecological momentary assessment. Annual Review of Clinical Psychology, $4,1-32$.

Solomon, S., \& Kington, R. (2002). National efforts to promote behavior-change research: Views from the office of behavioral and social sciences research. Health Education Research, 17, 495-499.

Stall, R. D., Coates, T. J., \& Hoff, C. (1988). Behavioral risk reduction for HIV infection among gay and bisexual men: A review of results from the United States. American Psychologist, $43,878-885$.

Stone, A., Shiffman, S., Atienza, A., \& Nebeling, L. (2007). The science of real-time data capture. Oxford: Oxford University Press.

Stover, E., \& Pequegnat, W. (2013). Chapter 1 "Establishing a research program in response to a public health crisis". In W.
Pequegnat \& E. Stover (Eds.), How to write a successful grant application: A guide for social and behavioral scientists. New York: Springer.

Sung, N. S., Crowley, W. F., Jr., Genel, M., Salber, P., Sandy, L., et al. (2003). Central challenges facing the national clinical research enterprise. JAMA, 289, 1278-1287.

The ENRICHD Investigators. (2000). Enhancing recovery in coronary health disease patients (ENRICHD): Study design and methods. American Heart Journal, 139, 1-9.

Thomson, W., 1st Baron Kelvin. (1871). The british association meeting at Edinburgh: Inaugural address of Sir William Thomson, LL.D, F.R.S., President. Nature, 4, 261-278. https://doi.org/ 10.1038/004261a0

U.S. Centers for Disease Control and Prevention. June 1, 2001. "First Report of AIDS". http://www.cdc.gov/mmwr/preview/mmwrhtml/ mm5021a1.htm

Volkow, N. D., et al. (2018). The conception of the ABCD study: From substance use to a broad NIH collaboration. Developmental Cognitive Neuroscience, 32, 4-7. https://doi.org/10.1016/j. den.2017.10.002

Weiss, S. M. (2013). Foreword: Early developments in the field of behavioral medicine. In M. D. Gellman, \& J. R. Turner (Eds). Encyclopedia of behavioral medicine. New York: Springer. https://link.springer.com/content/pdf/bfm\%3A978-1-4419-10059\%2F1.pdf.

Williams, R. B., Barefoot, J. C., Califf, R. M., et al. (1992). Prognostic importance of social and economic resources among medically treated patients with angiographically documented coronary artery disease. JAMA, 267, 520-524. 